\title{
Ciprofloxacin loaded castor oil based emulsion: Its antimicrobial, hematotoxicity and soft tissue pathophysiological study in Wister rats
}

\author{
A. Bamisaye ${ }^{1,2^{*}}$, C. O. Eromosele ${ }^{1}$, E. O. Dare ${ }^{1}$, and O. A. Akinloye ${ }^{3}$ \\ ${ }^{1}$ Department of Chemistry, College of Physical Sciences, Federal university of Agriculture, Abeokuta, Nigeria. \\ ${ }^{2}$ Department of Chemistry, Faculty of Basic Medical and Applied Sciences, Lead City University, Ibadan, \\ Nigeria. \\ ${ }^{3}$ Department of Biochemistry, College of Physical Sciences, Federal university of Agriculture, Abeokuta, \\ Nigeria. \\ Correspondence: abayomibamisaye@gmail.com; +2348033982982 \\ Received 19 May 2020; accepted 20 July 2020, published online 28 August 2020
}

\begin{abstract}
The emergence of nanocarrier for drug delivery has been flanked with great achievements in the field of nanomedicine. It is however unsafe to assume their toxicological safety. This necessitated examining the toxico-dynamics of ciprofloxacin loaded castor oil based emulsion $(\mathrm{COAB}+\mathrm{Cp})$. The emulsions were prepared by mechano-chemical process. The effects of $10 \mathrm{~mL}$ per $\mathrm{kg}$ of body-weight $(\mathrm{BW})$ of $\mathrm{COAB}+\mathrm{Cp}$ was estimated in Adult Wistar rats $(\mathrm{n}=10)$ for 21 days vis-à-vis a control set up, treated with equal volume of distilled water. The biochemical and haematological parameters were conducted with histopathology of the heart, kidney, spleen and liver. Also, the antimicrobial study on Bacillus. Subtilis (BS) was carried out using the agar well diffusion method. No observable abnormal change in BW gain of both test and control animals. Treatment of animals with $\mathrm{COAB}+\mathrm{Cp}$ did not cause any observable significant change at $\mathrm{P}>0.05$ in the blood-chemistry parameters and hematological indices. The photopathological examinations indicates that the histological architecture of vital organs (heart, liver, kidney and spleen) was not compromised in COAB $+\mathrm{Cp}$ treated animals. While the recorded value of minimum inhibitory concentration (MIC) and minimum bactericidal concentration $(\mathrm{MBC})$ of $\mathrm{COAB}+\mathrm{Cp}$ corroborated its mean zone of inhibition (ZI) values, signifying a better bioactivity of $\mathrm{COAB}+\mathrm{Cp}$ compared to $\mathrm{Cp}$ on $\mathrm{BS}$. $\mathrm{COAB}+\mathrm{Cp}$ has no cardiotoxic, hematotoxic and hepatotoxic effects on Wistar rats, with increased potency of the encapsulated $\mathrm{Cp}$ thus appears promising as a safe vehicle for oral delivery of ciprofloxacin.
\end{abstract}

Keywords: Emulsion; Nanocarrier; Photopathology; Cardiotoxic; Toxicokinetics

\subsection{Introduction}

Human being are classified as multicellular organisms [1]. These cells are suspended in a matrix; blood, and as such, the analysis of the blood reflects the state of the cells which are biomarker to the state of health of man or an organism [2,3]. Over the years, the quest to solve the problems associated with drug delivery necessitated the development of various means of its delivery. This will foster patient compliance as well as improve the therapetic potentials as well as the bioavailability of the encapsulated drugs without necessarily increasing the concentration $[4,5]$. On this note, colloids have played a vital role in which series of emulsion have been formulated. With various application in nanomedicine and drug delivery either as a carrier or for imaging purposes through which bioactive materials can be transported into the body system [6, 7] This is due to its excellent surface properties or characteristics, thereby acting as excipient in the manufacturing of drugs [8 -11]. In order to be suitable for this purposes, combination of other synthetic components (surfactant and co-surfactant) which has been approved as safe by Food and Drug Agency (FDA) are required to make up the formulation [12, 13]. It is therefore expedient to consider the safety of the mixture, that is, the formulations that makes up the drug carrier as well as the drug to be carried. Furthermore, $\mathrm{Cp}$ is a second generation fluoroquinolones that is used to treat gastrointestinal tract, respiratory tract and genitourinary tract infections. It functions by enzymatic-inhibition catalytic process to inhibit the growth of diseasescausing microorganisms through interfering with the replication process of DNA gyrase [14]. It is effective on Bacillus subtilis, a gram positive bacteria capable of growth within diverse environments including the gastrointestinal tracts. This microorganism is one of the main cause of pneumonia, pan-ophthalmitis, visceral abscess or musculoskeletal infections, and 
tissue necrosis $[15,16,17]$. In this study, the action of $\mathrm{COAB}+\mathrm{Cp}$ on Bacillus subtilis was to ensure that the drug retains its antimicrobial potential in the oil phase of the emulsion prior toxicity study of the drugloaded emulsion on Wistar rats. On this note, this

\subsection{Materials and Methods \\ 2.1 Materials}

Analytical grade ciprofloxacin from Sigma Aldrich, Germany. Polyethylene (20) sorbitanmonooleate (T 80 ), polyethylene (20) sorbitanmonolaurate (T 20); and polyehtylene glycol (PEG 400) (NOF, Shanghai) were purchased from Evergreen Chemical industry, Idumota Lagos, Nigeria. Freeze-dried Bacillus subtilis. The clinical isolates of Bacillus subtilis which were collected from Federal Medical Centre (FMC), Idi Aba, Abeokuta, Nigeria were provided by the Department of Microbiology, Federal University of Agriculture, Abeokuta, Nigeria.

\subsection{Emulsification}

The emulsification was carried out by weighing $0.075 \mathrm{~g}(0.3 \% \mathrm{w} / \mathrm{w})$ of $\mathrm{Cp}$ in a beaker containing $0.75 \mathrm{~g}(3 \% \mathrm{w} / \mathrm{w})$ castor oil. The mixture was homogenized until the drug was completely dissolved in the oil, then, $1.00 \mathrm{~g}(4 \% \mathrm{w} / \mathrm{w})$ of $\mathrm{T}$ $20,4.00 \mathrm{~g}(16 \% \mathrm{w} / \mathrm{w})$ of $\mathrm{T} 80$, and $1.00 \mathrm{~g}(4 \%$ $\mathrm{w} / \mathrm{w})$ of PEG 400 and $18.25 \mathrm{~g}(73 \% \mathrm{w} / \mathrm{w})$ of distilled-deionized water were gently added. The mixture was homogenized using a magnetic stirrer (Faithful Huanghua SH-4C) at $800 \mathrm{rpm}$ for $60 \mathrm{~min}$ $[18,19]$.

\subsection{Management of animals and experimenta design}

Ten adult Wistar rats, weighing between 100 and 120 $\mathrm{g}$ were purchased from the animal breeding unit of the Department of Physiology and Pharmacology, Lead City University, Ibadan, Nigeria. All procedures for maintenance and sacrifice (care and use) of animals were carried out according to the criteria outlined by the National Academy of Science published by the National Institute of Health [20] and approved by Lead City University Ethical Review Board with protocol identification number; LCU/ERB/AN0017. The animals were randomly assigned to two groups, I and II containing five (5) animals each $(n=5)$. The animals were acclimatized for two weeks before the commencement of the study. Group I animals served as control and group II animals were orally administered $\mathrm{COAB}+\mathrm{Cp}(10$ study aimed at evaluating the cytotoxicity of $\mathrm{COAB}+\mathrm{Cp}$ on the suspended cells in blood of Wistar rats as well as its pathological effects on the structures of the heart, kidney, spleen and liver.

$\mathrm{mL} / \mathrm{kg}$ bw) daily for a period of 21 days. After which they were sacrificed and blood samples and organs including the heart, liver, kidney and spleen were collected for analyses

\subsubsection{Biochemical assays}

The serum activity of alanine amino transferase (ALT) and aspartate amino transferase (AST) was estimated spectrophotometrically (Axiom, England) by Reitman and Frankel method [21], serum total protein and albumin levels were analysed using Randox kits (Randox Laboratories Limited, England) as described by Tietz, [22]. The level of globulin was obtained by difference. Whole blood haemoglobin concentration was spectrophotmetrically (Axiom, England) determined by Franco method [23] as described in cypress diagnostic Kit (Cypress Diagonistic, Belgium).

\subsubsection{Histopathological Analysis}

The tissues collected for histopathology retrieved from each rat were preserved in buffer $10 \%$ formalin solution for histopathological processing and examination. The fixed tissues were labeled accordingly, dehydrated by passing it through ascending grades of ethyl alcohol (70\%, 80\%, 90\% and $100 \%$ ) solutions and cleared in xylene solutions al baths to remove the alcohol, followed by infiltrating it in molten paraffin wax. Paraffin sections of the tissues were prepared and cut at 5 or $6 \mu \mathrm{m}$ thick with a rotary microtome and stained with haematoxylin and eosin according to Avwioro's method [24] the tissue sections were examined with light microscope.

\subsection{Antimicrobial Study \\ 2.4.1 Inoculums preparation}

The bacteria strain was prepared overnight at $37{ }^{\circ} \mathrm{C}$. The presence of turbidity in broth culture was adjusted equivalent to $0.5 \mathrm{McFarland}$ standards to obtain standard suspension by adding sterile normal saline in Mueller-Hilton agar slants. The McFarland 0.5 standard provides turbidity comparable to bacterial suspension containing $1.5 \times 10^{8} \mathrm{CFU} / \mathrm{mL}$ and used at different dilutions in the proposed evaluation tests. 


\subsubsection{Determination of Antibacterial activities} Antibacterial activities of the drug samples were evaluated by the well plate agar diffusion method using the earlier method with modifications [25]. determined by measuring the zone of inhibition around each well [26].

\subsubsection{Determination of minimum inhibitory} concentration (MIC)

The MIC of both the drug and drug loaded emulsions were determined by the tube dilution technique, using a modified method Junaid et al., [27]. The smallest concentration that inhibits the growth was taken as the MIC [28].

\subsection{Results and Discussion}

There was an observable significant difference at $\mathrm{P}<$ 0.05 in the mean $\mathrm{ZI}$ values of $\mathrm{COAB}+\mathrm{Cp}$ compared to $\mathrm{Cp}$ at concentration 500,125 and $62.15 \mathrm{mg} / \mathrm{mL}$ shown in Table 1. Also, the MIC and MBC of $\mathrm{COAB}+\mathrm{Cp}$ were found to be less than $\mathrm{Cp}$ which supports the ZI result as regards the effectiveness and improved bio-potency of $\mathrm{Cp}$ in the emulsion phase. This could be due to the surface characteristic and better permeation rate of drug loaded emulsion through the cell membranes' of the microorganism.[30, 31]. It was observed that the antimicrobial potential of both the drug and the drug loaded emulsion reduces as concentration of the treatment reduces.

Table 1: The antimicrobial activities showing the zone of inhibition (ZI) of drugs and drug loaded emulsion on Bacillus spp.

\begin{tabular}{llcl}
\hline $\begin{array}{l}\text { Conc. }(\mathrm{mg} / \\
\mathrm{mL})\end{array}$ & $\begin{array}{l}\text { COAB } \\
(\mathrm{mm})\end{array}$ & $\mathrm{Cp}(\mathrm{mm})$ & $\begin{array}{l}\mathrm{COAB}+\mathrm{Cp} \\
(\mathrm{mm})\end{array}$ \\
\hline 500 & 0 & $17.00 \pm 0.58^{* *}$ & $23.33 \pm 0.33^{* *}$ \\
250 & 0 & $16.67 \pm 0.33^{*}$ & $17.00 \pm 0.57^{\mathrm{a}^{*}}$ \\
125 & 0 & $12.33 \pm 0.30^{* *}$ & $15.00 \pm 0.50^{* *}$ \\
62.50 & 0 & $9.00 \pm 0.58^{*}$ & $11.00 \pm 0.40^{*}$ \\
31.25 & 0 & $6.00 \pm 0.57^{* *}$ & $8.000 \pm 1.00^{* *}$ \\
\hline $\begin{array}{l}\text { Data are means of three replicates }(\mathrm{n}=3): \text { mean } \pm \mathrm{SD}{ }^{* *} \text { Shows } \\
\text { significant difference at } \mathrm{P}<0.05 \text { while }{ }^{*} \text { Shows no significant difference }\end{array}$ \\
between Cp and COAB+Cp at P $>0.05$
\end{tabular}

\subsubsection{Determination of minimum bactericidal concentration (MBC)}

The MBC is the lowest concentration of antibiotic agent that kills at least $99.9 \%$ of the organism. $\mathrm{MBC}$ of $\mathrm{Cp}$ and $\mathrm{COAB}+\mathrm{Cp}$ on the clinical isolate of Bacillus subtilis were carried out according to Doughari method [29].

\subsection{Statistical Analysis}

All statistical analysis were performed using SPSS software 16.0 (SPSS Inc., Chicago, IL) and Prism Graphpad 6.0. The level of significance was set at P < 0.05 . The results are presented as the mean \pm SD.

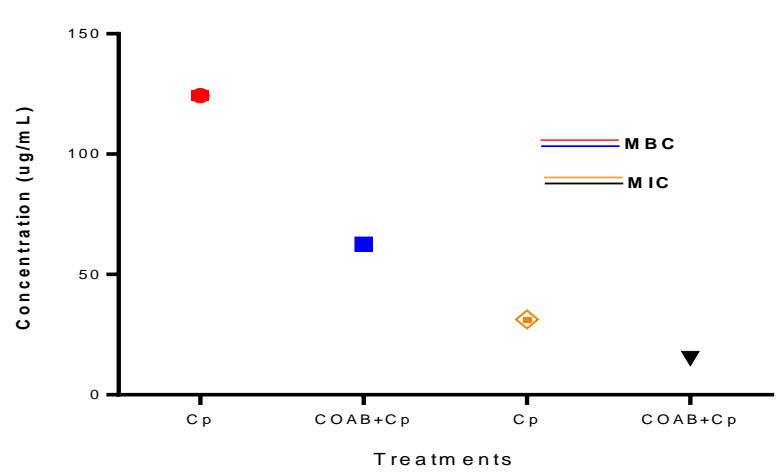

Figure 1: The minimum bactericidal concentration (MBC) and minimum inhibitory concentration (MIC) of $\mathrm{Cp}$ and Cp-loaded nanoemulsion on Bacillus spp.

Some of the signs and symptoms of unhealthy side effects of drugs or drug vehicles include excessive weight gain/loss. In this study, treatment of the rats with $\mathrm{COAB}+\mathrm{Cp}$ compared with the control group as shown in Table 2 revealed a steady increase in weight gain of the animal. This however suggested no weigh loss in the test animals which shows that $\mathrm{COAB}+\mathrm{Cp}$ does not interfere with food metabolism, nutrient absorption and utilization.

Table 2: Effects of $\mathrm{COAB}+\mathrm{Cp}$ on Average Body Weight of the Experimental Animals

\begin{tabular}{lll}
\hline Days & Control $(\mathbf{K g})$ & COAB+Cp $(\mathbf{K g})$ \\
\hline 1 & $121.10 \pm 10.00$ & $125.00 \pm 3.53$ \\
3 & $125.90 \pm 9.61$ & $127.00 \pm 7.07$ \\
5 & $127.00 \pm 10.00$ & $128.40 \pm 9.90$ \\
7 & $133.05 \pm 12.53$ & $131.60 \pm 9.19$ \\
9 & $141.75 \pm 10.41$ & $134.20 \pm 7.78$ \\
\hline
\end{tabular}




\begin{tabular}{lll}
\hline 11 & $145.70 \pm 12.10$ & $134.40 \pm 10.61$ \\
13 & $151.35 \pm 8.16$ & $136.20 \pm 9.90$ \\
15 & $151.75 \pm 10.41$ & $138.80 \pm 12.02$ \\
17 & $154.15 \pm 11.93$ & $140.20 \pm 8.49$ \\
19 & $157.00 \pm 13.23$ & $141.00 \pm 7.07$ \\
21 & $161.10 \pm 13.00$ & $145.00 \pm 7.10$ \\
\hline $\mathrm{n}=5$, Data are represented as the mean $\pm \mathrm{SD}$
\end{tabular}

Furthermore, damage to soft tissues particularly liver is often characterized by abnormality in serum activity of enzyme markers such as ALT, AST and ALP. High levels of bilirubin and urea, as well as marked decrease in white blood cells and hemoglobin content may be due to lyses of red blood cells [32]. Liver is one of the vital organs in the body that is prone to toxicity due to its function as the primary site for the metabolism of most ingested substances in the body [33]. During the process of hepatic metabolism, there is a tendency for the build-up of harmful toxic substances that are capable of altering the morphology of the liver thereby resulting to the leakage of enzymes (ALT, AST and ALP) from the cytosol of the hepatocytes into the circulation [34, 35]. These enzymes, particularly ALT and AST are clinical markers that determines the functionality of liver. Also, total plasma protein which is a sum of albumin and globulin are essential blood parameter in the effective functioning of the body's system. Hence, it is expedient that its plasma concentration exists within certain clinically defined range. Marked deviations from this physiological concentration range could trigger unhealthy metabolic state of the organism in question. The results obtained in this study as shown in Figure 2 proposed that there was no observable significant difference in all the serum parameters of the treated animal when compared to the control at $\mathrm{P}>0.05$. Except in urea which a significant difference was observed between the control and treated rats. This was suggested to be due to the protein content of the treatment.

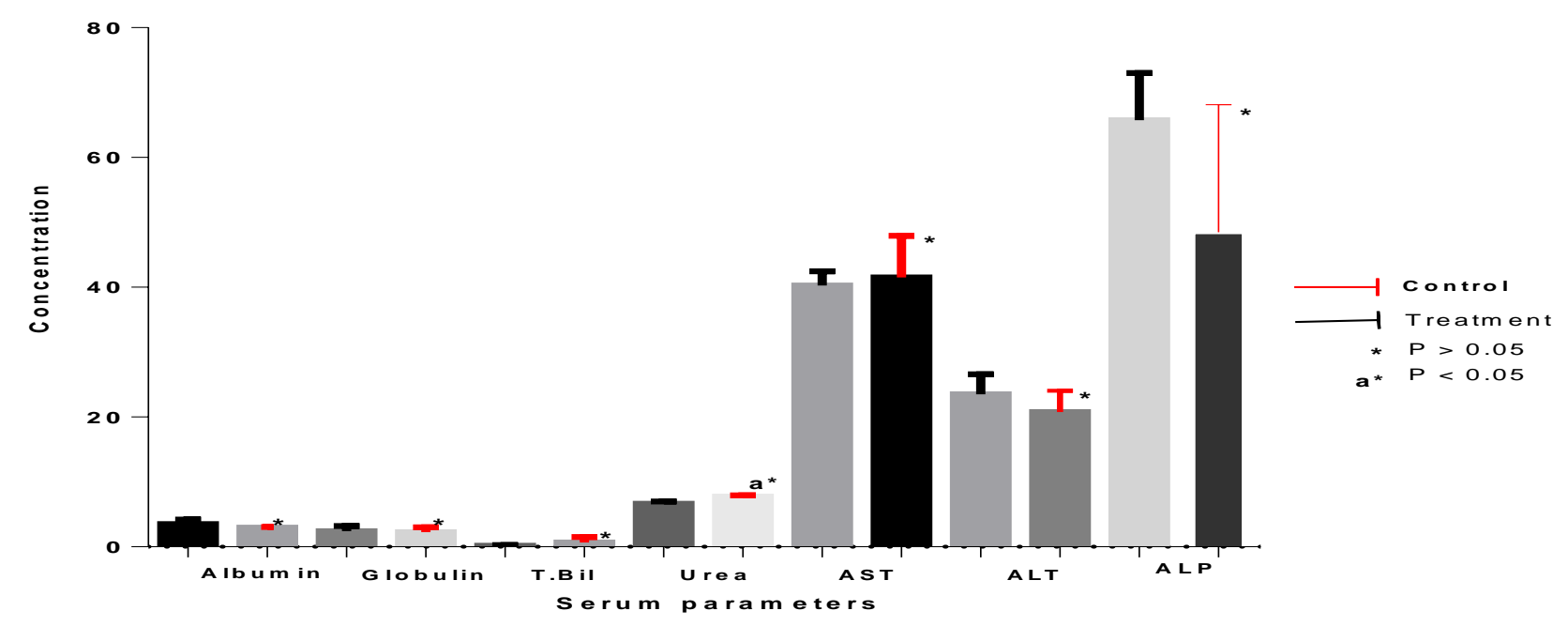

Figure 2: The Serum parameters of control and Cp-loaded emulsion of Wistar rats

Blood is regarded as life fluid because it is made up of series of suspended cells and these cells are essential life supporting organs which helps in maintaining homeostatic process. The state of the body and its functionality could be reflected by the deviation from the norm in the following bloodrelated indices such as total protein level, enzyme activity, hematological profile (leucocytes, erythrocytes, neutrophils, and hemoglobin and lymphocyte counts). These are therefore the primary pathological reflectors of the health status of humans and animals [36, 37]. The response of the body defense mechanism against a foreign invasive pathogenic substance is reflected by the increase in the secretion of these immunogenic parameters; Leucocytes, neutrophils, lymphocytes and monocytes in which their protective response is apt. Conversely, the protective mechanism provided by these body defense mechanism could be suppressed due to the persistence in the toxicity of the invasive substance, thereby resulting in the reduction of these parameter through a process described as immunological suppression. This could however result to severe compromise in the normal physiological functions of the body system which can expose the animal to further toxin and pathogenic attacks resulting to 
death. The result of the hematological parameter in this study presented in Table 2 indicates that there was no observable significant difference in the hematological parameters as shown in the test of significance noted at $\mathrm{P}<0.05$. This however connotes that $\mathrm{COAB}+\mathrm{Cp}$ does not pose any threat to the functionality of the treated animals compared to the control animals.

Table 3: Hematological parameters of control and $\mathrm{COAB}+\mathrm{Cp}$

\begin{tabular}{lllc}
\hline Parameters & Control & Treatment & P value \\
\hline PCV (\%) & $40.00 \pm 5.2^{*}$ & $45.00 \pm 1.47^{*}$ & 0.3928 \\
Hb (g/dl) & $15.95 \pm 0.065^{*}$ & $14.10 \pm 0.87^{*}$ & 0.0777 \\
RBC x10 $1 \mathbf{1 2}$ & $8.175 \pm 0.28^{*}$ & $8.075 \pm 0.46^{*}$ & 0.8587 \\
WBC x10 & $6.825 \pm 0.28^{*}$ & $5.650 \pm 0.55^{*}$ & 0.1070 \\
Neutrophils (\%) & $29.25 \pm 1.65^{*}$ & $29.50 \pm 4.63^{*}$ & 0.9611 \\
Lymphocytes (\%) & $67.25 \pm 1.38^{*}$ & $67.50 \pm 4.63^{*}$ & 0.9604 \\
Eosinophils (\%) & $1.000 \pm 0.00^{*}$ & $0.5000 \pm 0.29^{*}$ & 0.1340 \\
Monocytes (\%) & $1.000 \pm 0.00^{*}$ & $1.500 \pm 0.30^{*}$ & 0.1350 \\
Basophils (\%) & $1.500 \pm 0.28^{*}$ & $1.000 \pm 0.00^{*}$ & 0.1340 \\
MCV (f/L) & $48.45 \pm 4.79^{*}$ & $56.06 \pm 2.20^{*}$ & 0.1988 \\
MCH (pg) & $19.58 \pm 0.70^{*}$ & $17.58 \pm 1.16^{*}$ & 0.1902 \\
MCHC(g/dl) & $42.06 \pm 5.57^{*}$ & $31.28 \pm 1.22^{*}$ & 0.1077 \\
\hline
\end{tabular}

Data are means of four replicates $(\mathrm{n}=4) \pm$ SEM; ${ }^{* *}$ Shows a significant difference at $\mathrm{P}<0.05$ while Shows no significant difference between Control and $\mathrm{COAB}+\mathrm{Cp}$ at $\mathrm{P}>0.05$. $\mathrm{Hb}$, hemoglobin; $\mathrm{PCV}$, packed cell volume; $\mathrm{RBC}$, red blood cell; $\mathrm{MCV}$, mean corpuscular volume; $\mathrm{MCH}$, mean corpuscular hemoglobin; MCHC, mean corpuscular hemoglobin concentration; WBC, white blood cell

Furthermore, the pathological study of the soft tissues is an important parameter that is very essential and cannot be underestimated. Its assessment helps to reveal the impacts of the xenobiotic substance on the soft tissue's proper functionality. The observation in the photomicrographs of the section of heart in Plates $3 \mathrm{~A}$ and $\mathrm{B}$ showed a normal appearance of the myofibers. Likewise the liver and spleen. More so, the kidney is an important organ that houses the nephron, which is responsible for ultrafiltration and reabsorption of fluid in the body. Although, earlier studies reported that acute kidney injury is as a result of tubular necrosis but in recent time, studies have shown that necrosis is not the main form of cell death [38]. Persistent use of drug on daily bases could also result to the alteration of the physiological structure of kidney due to its function as a filter. Proper hydration is one of the precautionary measures to reduce the effect of drugs on the kidney [39]. In this study, mild congestion of interstitial blood vessels, degeneration and necrosis of tubular epithelia tissue was observed in the photomicrograph of a section of kidney treated with $\mathrm{COAB}+\mathrm{Cp}$ (Plate $2 \mathrm{~B})$. This could be due to the persistent administration of treatment as well as poor intake of water for proper hydration of the treated rats. Physiological alteration in the morphology of the spleen and liver was not observed.
This study indicates that administration of $\mathrm{COAB}+\mathrm{Cp}$ to animals did not jeopardize the morphology of the liver as substantiated by the photomicrograph of the treated animals (Plate 4G) compared to the control counterparts (Plate 4H). It was noted that the pathological studies of the soft tissues examined in this study was in line with the hematological and serum chemistry's results. This shows that the functionality and the integrity of the blood suspended cells were not jeopardized. This findings further attests to the apparent safety of $\mathrm{COAB}+\mathrm{Cp}$ as a potential vehicle for drug delivery and targeting.

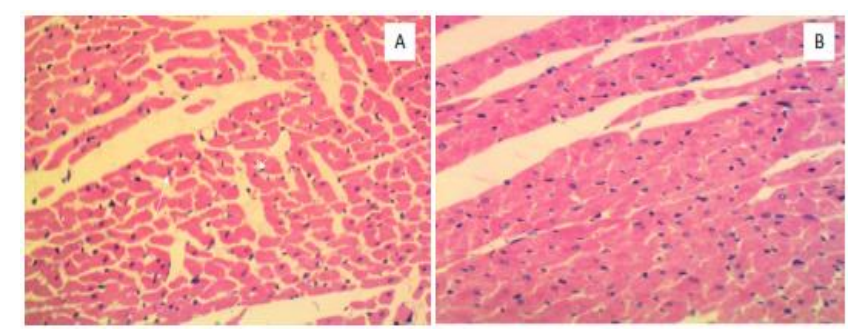

Plate 1: Sections of the heart from control (A) and treated $(B)$ rats $(\mathrm{x} 400 ; \mathrm{H} \& \mathrm{E})$. 


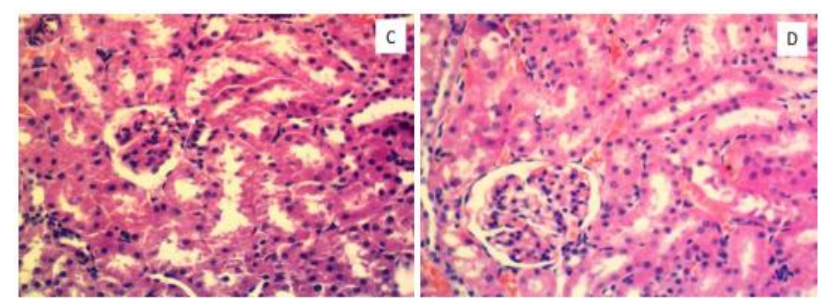

Plate 2: Sections of the kidney from control (C) and treated (D) rats $(x 400 ; \mathrm{H} \& \mathrm{E})$

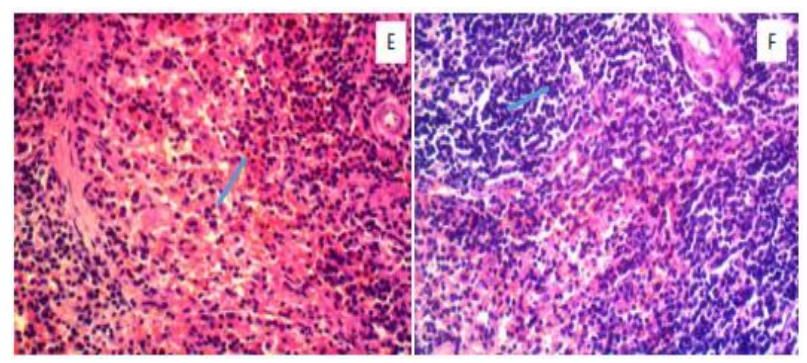

Plate 3: Sections of the spleen from control (C) and treated (D) rats $(x 400 ; H \& E)$

\subsection{Conclusion}

The findings of this study shows that $\mathrm{COAB}+\mathrm{Cp}$ has the potential to encapsulate the drug due to its effects on Bacillus subtilis. And at the investigated

\section{REFERENCES}

1. C. Boitani, S. Di Persio, V. Esposito and E. Vicini (2016). Spermatogonial cells: mouse, monkey and man comparison, In Seminars in cell \& developmental biology, Academic Press, 59, $79-88$.

2. C. F. Friedman, M. A. Postow (2016). Emerging tissue and blood-based biomarkers that may predict response to immune checkpoint inhibition, Current oncology reports, 18, 4 - 21.

3. W. L. C. Ribeiro, A. L. F. Camurça-Vasconcelos (2015). In vitro effects of Eucalyptus staigeriana nanoemulsion on Haemonchus contortus and toxicity in rodents, Veterinary parasitology, 212, 444-447.

4. M. Taleb, N. Abdeltawab, R. Shamma, S. Abdelgayed, S. Mohamed, M. Farag, M. Ramadan and L. Origanum vulgare (2018).

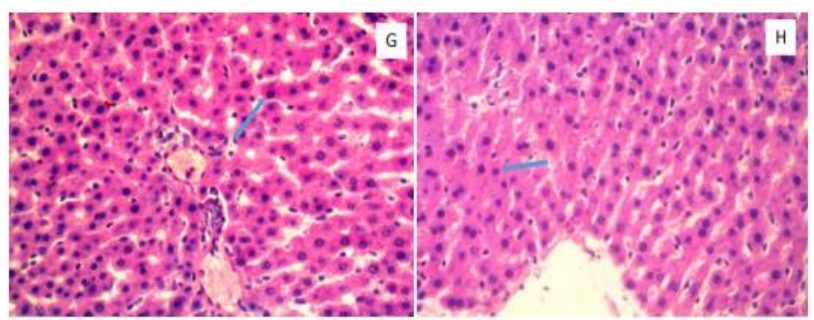

Plate 4: Sections of the Liver from control (E) and treated $(\mathrm{F})$ rats $(\mathrm{x} 400 ; \mathrm{H} \& \mathrm{E})$

dosage of $10 \mathrm{~mL} / \mathrm{kg} \mathrm{BW}$, the emulsion was observed to have no cardiotoxic, hematotoxic and hepatotoxic effects on Wistar rats, without any obvious alterations in the physiological structure of the soft tissues and as such appears promising as a safe vehicle for oral drug delivery and targeti

Essential Oil as a Potential Anti-Acne Topical Nanoemulsion-In Vitro and In Vivo Study, Molecules, 23, 2164.

5. P. Alam, M. J. Ansari, M. K. Anwer, M. Raish, Y. K. Kamal, and F. Shakeel (2017). Wound healing effects of nanoemulsion containing clove essential oil. Artificial cells, nanomedicine, and biotechnology, 45, 591-597.

6. J. M. Janjic and V. S. Gorantla (2017). Peripheral nerve nanoimaging: monitoring treatment and regeneration, The AAPS journal, 19, 1304-1316.

7. A. Kumar, A. Tan, J. Wong, J. C. Spagnoli, J. Lam, B. D. Blevins, and H. Liu (2017). Nanotechnology for neuroscience: promising approaches for diagnostics, therapeutics and brain activity mapping, Advanced functional materials, $27,5-17$ 
8. X. Yan, B. He, L. Liu, G. Qu, J. Shi, L. Hu and G. Jiang (2018). Antibacterial mechanism of silver nanoparticles in Pseudomonas aeruginosa: proteomics approach, Metallomics, 10, 557-564

9. M. Yamanaka, K. Hara and J. Kudo (2005). Bactericidal actions of a silver ion solution on Escherichia coli, studied by energy-filtering transmission electron microscopy and proteomic analysis, Applied and Environmental Microbiology, 11, 7589

10. S. R. Mudshinge, A. B. Deore, S. Patil and C.M. Bhalgat (2011). Nanoparticles: emerging carriers for drug delivery, Saudi Pharmaceutical Journal, $19,129-141$

11. A. Y. Kim and J. C. Berg (2000). Fractal heteroaggregation of oppositely charged colloids. Journal of colloid and interface Science, $229,607-614$.

12. R. E. Sloup, R. J. Cieza, D. B. Needle, R. B. Abramovitch, A. G. Torres, C. M. Waters (2016). Polysorbates prevent biofilm formation and pathogenesis of Escherichia coli O104: H4, Biofouling, 32, 1131-1140.

13. K. S. Valeur, S. A. Hertel, K. E. Lundstrøm, and H. Holst (2017). Safe excipient exposure in neonates and small children-protocol for the SEEN project, Dan Med. J., 64, A5324.

14. D. C. Hooper and G. A. Jacoby (2016). Topoisomerase inhibitors: fluoroquinolone mechanisms of action and resistance, Cold Spring Harbor perspectives in medicine, 6, 9-18

15. C. Massip, C. Mathieu, C. Gaudru, V. Miaut, P. Floch, E. Oswald, and H. Guet-Revillet (2018). In vitro activity of seven $\beta$-lactams including ceftolozane/tazobactam and ceftazidime/avibactam against Burkholderia cepacia complex, Burkholderia gladioli and other non-fermentative Gram-negative bacilli isolated from cystic fibrosis patients, Journal of Antimicrobial Chemotherapy, 74,525-528.

16. H. E. Pearson (1970). Human infections caused by organisms of the Bacillus species, American Journal of clinical pathology, 53, 506-515.
17. R. Sliman. S. Rehm and D. M. Shlaes (1987). Serious infections caused by Bacillus species, Medicine, 66, 218-223.

18. O. A. Bamisaye, C. O. Eromosele, F. O. Oladoyinbo, O. A. Akinloye, and O. E. Dare (2018). Development of oil-in-water (O/W) nanoemulsion formulations for spontaneous transdermal delivery of ciprofloxacin, Covenant Journal of Physical and Life Sciences, 5, 2.

19. S. Tri, A. Aldy and Satrialdi (2014). Development of transdermal nanoemulsion formulation for simultaneous delivery of protein vaccine and Artin-M Adjuvant. International, Journal of Pharmacy and Pharmaceutical Sciences, 6, 536-541.

20. NIH Publication Number 04-4158 February 2010 Available at <http://www. win.niddk.nih.gov>.

21. S. Reitman, and S. A. Frankel (1957). Colorimetric method for the determination of serum glutamic oxalacetic and glutamic pyruvic transaminases, American journal of clinical pathology, 1, 56-63.

22. N. W. Tietz (1995). Clinical guide to laboratory tests. WB Saunders press.

23. R. S. Franco, M. Weiner (1984) inventors; Franco Robert S, assignee. Method for altering red blood cell function and survival. United States patent US 4,478,824.

24. O. G. Avwioro (2002). Histochemistry and Tissue Pathology, Principles and Techniques, First Edition. Claverianum Centre Ibadan, 51-140

25. P. Aida, V. Rosa, F. Blamea, A. Thomas and C. Salvador (2001). Parauuan plants used in traditional medicine, Short Communication. Journal of Ethnopharmacology, 93-98

26. National Committee for Clinical Laboratory Standards (NCCLS) (1990). Method for antimicrobial susceptibility testing. Man. Clinical Microbiology 5th Edition 
27. S. A. Junaid, A. O. Olabode, F. C. Onwuliri, A. E. J. Okworiu and S. E. Agina (2006). The antimicrobial properties of Ocimum gratissimum extracts on some selected bacterial gastrointestinal isolates, African Journal of Biotechnology, 5, 2315-2321.

28. F. Geo, J. S. B. Brooks and A. M. Stephen (2001). Jawetz, Melnick and Adelberg's Medical Microbiology, 22: 607.

29. J. H. Doughari, M. S. Pukuma, and N. De (2007). Antibacterial effects of Balanites aegyptiaca L. Drel. and Moringa oleifera Lam. on Salmonella typhi. African Journal of Biotechnology, 6, 22122215

30. S. J Lee and D.J. McClements (2010). Fabrication of protein-stabilized nanoemulsions using a combined homogenization and amphiphilic solvent dissolution/evaporation approach, Food Hydrocolloids, 24, 560 - 569

31. B. P. Inayat and S. Mallikarjuna (2012). Nanoemulsion system for transdermal delivery of tamoxifenciterate: design, characterization effect of penetration enhancer and in vivo studies. Journal of Nanomaterials and Biostructure 7, 1373-1387.

32. G. Yuan, S. Dai, Z. Yin, H. Lu, R. Jia, and J. Xu (2014).Toxicological assessment of combined lead and cadmium: Acute and subchronic toxicity study in rats. Food and Chemical Toxicology, $65,260-8$.

33. X. Gu and J. E. Manautou (2014). Molecular mechanisms underlying chemical liver injury, Expert reviews in molecular medicine, 14.

34. A. Rašković, N. Pavlović, M. Kvrgić, J. Sudji, G. Mitić, L, Čapo and M. Mikov (2015). Effects of pharmaceutical formulations containing thyme on carbon tetrachloride-induced liver injury in rats. BMC complementary and alternative medicine. $15,442$.

35. O. M. Ighodaro, A. M. Adeosun, B. A. Adeoye and O. Gabriel (2017). Total Antioxidant Capacity of Sapium ellipticum (Hochst) Pax Leaf Extract, and Its Antioxidant Enzymes Potential in
Free-Radical Systems in vitro, Journal of American Science, 13(7).

36. L. A. Mary, Giknis B. Charles and Clifford (2008). Clinical Laboratory Parameters for Ctrl:WI (Han) rats. Charles River Laboratory,

37. E. T. Anderson, M. K. Stoskopf, J. A. Morris Jr, E. O Clarke, and C. A. Harms (2010). Hematology, plasma biochemistry, and tissue enzyme activities of invasive red lionfish captured off North Carolina, USA. Journal of Aquatic Animal Health, 4, 266-73.

38. S. M. Sancho-Martínez, J. M. López-Novoa and F. J. López-Hernández (2015). Pathophysiological role of different tubular epithelial cell death modes in acute kidney injury. Clinical kidney journal, 8, 548-559.

39. B. Joob (2016). Acute kidney injury due to ciprofloxacin for treatment of acute pyelonephritis. Journal of nephropharmacology, 5: 73 . 